\title{
İnfertilite tedavisinin psikolojik etkileri ve tedavi sürecindeki psikolojik müdahaleler
}

\author{
Ece Bekaroğlu ${ }^{1}$
}

\author{
Anahtar kelimeler \\ infertilite, psikolojik \\ süreçler, psikolojik \\ müdahaleler
}

\section{Key words}

infertility, psychological processes, psychological interventions

\begin{abstract}
$\ddot{\mathrm{O} z}$ Dünya genelinde çocuk sahibi olmak isteyen çiftlerin \%8-12'si çeşitli sebeplerle infertilite (kısırlık) tanısı almaktadır. Bu çiftlerin \%10-12'sinde, yaşanılan probleme ilişkin fizyolojik bir açıklama bulunamamakta ve infertilite tanısı çoğu zaman psikolojik sebeplere atfedilmektedir. İnfertilite tanısını alan kişiler, bu tanı tıbbi bir müdahale gerektirdiği için biyolojik anlamda; tanı istedikleri halde çocuk sahibi olamamaya yol açtığı için sosyokültürel bağlamda ve tanının ortaya çıkarabildiği psikolojik rahatsızlıklar boyutunda infertiliteden etkilenmektedir. Tedaviye hazır olma konusunda biyopsikososyal süreçler kadar, kadının tedavinin gerektirdiklerini içsel bir çatışma olmadan kabul ederek tedaviye hazır olması; bir başka ifadeyle, kadının deneyimlediği psikolojik süreçler de dikkate alınmalıdır. Psikoloji tarihinde infertilite, öncelikle bilinçaltı savunma mekanizmaları ve çatışmalarla ele alınmış; ardından döngüsel psikoloji modeli, psikolojik sonuçlar modeli, psikososyal bağlam modeli, keder ve yas yaklaşımı, bireysel kimlik kuramları, aile sistemleri yaklaşımı ve evre modelleri ile açıklanmaya çalışılmıştır. Bu yaklaşımlar bağlamında psikoterapi hedefi tedavi öncesinde, tedavi sırasında ve tedavi sonrasında bireylerin bu yaşantıya uyum sağlama becerilerini artırmak ve travmatik etkiler yerine psikolojik büyüme ile süreci tamamlamalarını sağlamaktır. Psikolojik değerlendirmenin ardından tedavi klinik psikolog tarafından uygun görülen bireysel, çift/aile, destek grubu ya da terapi grubu ile sağlanabilir. Bu derleme çalışmasının hedefi, infertiliteye özgü psikoloji tarihi bakış açısından yararlanarak, infertilite tedavisini alan kişilerle çalışan psikologlara yaşanabilecek psikolojik süreçler ve müdahale yöntemleri konusunda bilgi vermektir.
\end{abstract}

\begin{abstract}
Psychological effects of infertility treatment and psychological interventions in the treatment process

All around the world, $8-12 \%$ of the couples who want to have children are diagnosed with the infertility. 10-12\% of these couples do not have an explanation for the reason of their diagnosis; therefore, infertility diagnosis is usually attributed to psychological processes. People who have the infertility diagnosis are affected at biological, sociocultural and psychological levels. In terms of readiness to treatment, the biopsychosocial processes as well as the psychological processes of the women should be taken into account. In the history of psychology, infertility has been initially explained by unconscious defense mechanisms and conflicts; and later, by psychological cyclical model, psychological consequences model, psychosocial context model, grief and bereavement approaches, individual identity theories, family systems approach and stage models. In this context, the aim of infertility psychotherapy is to enhance adaptation skills and psychological growth (rather than psychological trauma) before, during, and after infertility treatment. After psychological assessment, treatment can be provided with the appropriate individual level, couple/family level, support group or therapy group. The aim of this review is to inform psychologists working with infertility treatment about psychological processes and intervention methods in the light of infertility specific history of psychology.
\end{abstract}

Bekaroğlu, E. (2018). İnfertilite tedavisinin psikolojik etkileri ve tedavi sürecindeki psikolojik müdahaleler. Klinik Psikoloji Dergisi, 2(3), 153-159.

\begin{tabular}{ll}
\hline Ece Bekaroğlu • ecetathan@ gmail.com & Geliş tarihi: 03.07.2018 \\
${ }^{1}$ Psk. Dr., Ankara Hacı Bayram Veli Üniversitesi, Edebiyat & Kabul tarihi: 25.09.2018 \\
Fakültesi, Psikoloji Bölümü, D Blok 2/221, Ankara. & \\
& \\
& Klinik Psikoloji Araştırmaları Derneği $\cdot$ KPAD 2018
\end{tabular}


İnfertilite (kısırlık) kadın ve erkeğin üreme organları ile ilgili tıbbi bir problemdir, ancak 1930'lu y1llardan itibaren infertilitenin psikolojik boyutu, infertiliteyi psikoloji alanında çalışan bilim insanlarının da incelediği bir alan haline getirmiştir. Doğal yollarla çocuk sahibi olamayan çiftlerin, teknolojik gelişmelerle birlikte suni üreme yöntemleri kullanılarak çocuk sahibi olmaları yaygınlaşsa da infertilite tedavisi öncesinde, tedavi sırasinda ve sonrasinda psikolojik olarak olumsuz etkilenebildikleri ve psikolojik destekten fayda sağlayabildikleri belirtilmiştir.

\section{İnfertilitenin tanımı, sebepleri ve biyopsikososyolojik çerçevesi}

İnfertilite 12 aylık korunmasız cinsel ilişkiye rağmen, gebeliğin oluşmaması (Lykeridou, Gourounti, Deltsidou, Loutradis ve Vaslamatzis, 2009) ya da gebeliğin sağlıklı bir doğumla tamamlanamaması süreci (Speroff, Glass ve Kase, 1994) için kullanılan bir kavramdır. Dünya genelinde çocuk sahibi olmak isteyen çiftlerin $\% 8-12$ 'si infertilite tanısını almakta (Population Council, 2004), benzer şekilde Türkiye'de bu oran evli çiftlerde yaklaşık \%10 olarak belirtilmektedir (Turkish Medical Assosiation, 2006).

Fisher, Hammerberg ve Baker'in (2008) çalışmasina göre sadece erkekten ya da sadece kadından kaynaklanan infertilite oranı eșit ve yüzde \%30 iken kadın ve erkek kaynaklı infertilite oranı \%25, bir sebeple açıklanamayan infertilite oranı ise \%15 olarak bulunmuştur. Tibbi sebeple açılanamayan bu oran gerekli tanı testleri yapılıp, tedavi yürütüldüğü halde gebelikle sonuçlanmayan vakalardan oluşmuştur ve bu durum çoğunlukla psikolojik sebeplere atfedilmiştir. Türkiye'de yürütülmüş güncel bir çalışmada ise kadından kaynaklanan infertilite oran $1 \% 27$, erkekten kaynaklı infertilite oran1 \%25, çiftten kaynaklanan oran $\% 13$, açılanamayan infertilite oran1 ise \%35 olarak belirtilmiştir (Altıntop ve Kesgin, 2018).

Kadında üremeye ilişkin problemler, kadının üreme döngüsü, fallop tüpü tıkanıklığı ya da hasarı, endometriyozis (rahim içerisindeki tabakaların rahim dışında gelişmesi), yumurtlama problemleri, rahimdeki kötü huylu tümörler, erken menopoz, tiroid problemleri ve ileri yaştan kaynaklanabilir (Deyhoul, Mohamaddoost, Hosseini ve Dezelic, 2017; Mayo Clinic, 2011). Erkeklerde infertilite sebepleri ise sperm üretimi ya da işlevi ile ilgili problemler, erkek tüplerine ve üreme organlarına ilişkin faktörler, çevresel faktörler ve yaş ile ilişkili olabilir (Deyhoul ve ark., 2017; Mayo Clinic, 2011).

İnfertilite tanısını alan kişiler ya da çiftler yaşadıkları sağlık problemi ile ilgili olarak biyolojik, sosyal ve psikolojik olarak olumsuz yönde etkilenebilirler. Tibbi durumu ve sebepleri öğrenebilmek için uygulanan test yönergeleri fiziksel olarak zorlayıcı olabilir. Testlerin ardından tedavi hormonal terapiyi, aşılamayı, tüp bebek tedavisini gerektirebilir (Watkins ve Baldo, 2004).

Sosyolojik perspektiften bakıldığında, toplumlar çocuğun doğumuna büyük bir değer atfederler (van Balen ve Bos, 2004). Benzer şekilde Türk toplumunun aile yapısında çocuk önemli bir yere sahiptir. $\mathrm{Bu}$ sebeple, Türkiye'deki birçok çift için çocuk sahibi olmak evliliğin ilk amaçlarından biri olarak görülmektedir (Yeşiltepe Oskay, Kızılkaya Beji ve Serdaroğlu, 2010). İnfertil çiftler, aile buluşmaları ve ritüellerinde stres yaşayabilir, kendilerine infertiliteyi ve çocuk sahibi olmamayı hatırlatacağı için bu buluşmalara katılmamayı tercih edebilirler (Cooper-Hilbert, 1998). Çocuk sahibi olmadıkları için arkadaş ve aile buluşmalarına katılmamak izolasyona, yalnızlığa; kıskançlık, imrenme ya da öfke gibi duygulara sebep olabilir (Watkins ve Baldo, 2004). İnfertilitenin biyolojik ve sosyolojik etkilerinin yanı sıra, psikolojik etkilerinin yüksek seviyede kaygl (Drosdzol ve Skrzypulec, 2009; Karjane, Stovall, Berger ve Svikis, 2008; Lykeridou ve ark., 2009), depresyon (Coleman, Morison, Paine, Powell ve Walraven, 2006; Drosdzol ve Skrzypulec, 2009; Noorbala, Ramezanzadeh, Abedinia ve Naghizadeh, 2009), aleksitimi (Lamas ve ark., 2006) ve cinsel fonksiyon problemleri (Yeşiltepe Oskay, Kızılkaya Beji ve Serdaroğlu, 2010) ile ilişkilendirildiği ve yaşam doyumunu (Daniluk ve Tench, 2007; Schwerdtfeger, 2009), özgüveni (Daniluk ve Tench, 2007; Schwerdtfeger, 2009), evlilik doyumunu azalttığı (Daniluk ve Tench, 2007) ilgili alanyazında belirtilmiştir.

Tedaviye hazır olma konusunda tarihsel zamanlama ve kadının psikolojik zamanlaması ayrı ayrı dikkate alınmalıdır. Bir yıldır korunmasız cinsel ilişki ile çocuk sahibi olamayan çiftlerin doktora başvurmalarına; tanının ardından ekonomik süreçlerini ve beklentilerini gözden geçirerek tedaviye başlamalarına tarihsel zamanlama adı verilir. Kadının psikolojik zamanlaması ise kadının tedavi olmadan doğal yollarla çocuk sahibi olamayacağı düşüncesinin güçlüğünü ve tedavinin gerekliliğini kabul etme ya da reddetme gibi içsel çatışma yaşamasından etkilenebilir. Kadın, tedavinin kendisine olan fiziksel, duygusal ve maddi yüklerini sorgulayıp, çatışmaları çözümleyip, bunları kabul ettiğinde kadının psikolojik zamanlamasının da tedaviye uygun olduğu belirtilebilir (Şensözen, 2010).

Boivin'in (2003) infertilite tedavisinde psikolojik süreçleri ele alan alanyazını incelediği çalışmasında üç ana soru sorulmaktadır. İlk soru, "İnfertilite tedavisi sirasinda uygulanan psikososyal müdahaleler kişilerin iyilik haline etki etmekte midir?" Çalışmada, araştırmaların psikososyal müdahalelerin, kişilerarası ilişkileri değiştirme ya da düzenleme yerine, kişilerin olumsuz duygularını azaltmalarında etkili olduğunu bulduğu ifade edilmiştir. İkinci soru, "Psikososyal 
müdahaleler gebe kalma ihtimalini artırmakta mıdır?" Çalışmada, hamile kalma olasılığının psikososyal müdahalelerden etkilenmediği belirtilmiştir. Son soru ise şudur: "Bazı psikososyal müdahale yöntemleri diğerlerine göre daha mı etkilidir?" Psikoeğitim içeren ve gevşeme egzersizleri gibi becerileri geliştiren grup terapisi müdahalelerinin, duygu ifadesi ve infertilitenin getirdiği duygu ve düşüncelerin tartışıldığ 1 danışmanlık müdahalelerinden olumlu değişim geliştirmede daha etkili olduğu açıklanmıştır. Ayrıca, belirtilen etkili müdahale tekniklerinden kadın ve erkeklerin eşit seviyede yarar sağladığ 1 ifade edilmiştir.

\section{İnfertilitenin psikolojik etkileri}

İnfertilitenin psikolojik etkilerini inceleyen ilk teorilerden Freudyen psikanalitik bakış açısı, bireylerin çözülmemiş çatışmalarının ve bilinçaltı savunma mekanizmalarının kısırlığa sebep olabileceğini ya da katkıda bulunabileceğini belirtmiştir. Bu bağlamda psikojenik infertilite modeli 1930'larda Amerika Birleşik Devletleri'nde ortaya çıkmıştır (Benedek, 1952). O dönemlerde infertilite problemlerinin \%30'unun sebebi bilinmiyor, tedavi sağlanamıyordu. $\mathrm{Bu}$ yüzden, olası sebepler ve tedaviler için psikolojik açıklamalar yapmak anlamlı bulunuyordu. Yine de teorilerin büyük bir kısmı kadınlarda, anneliğe ilişkin nevrotik duyguların ya da kendi annelerinin yaklaşımlarının, annelik rolüne engel olduğu yaklaşımını benimsiyordu. Fischer (1953) kadınlarda infertiliteye sebep olabilecek iki kişilik yapısı olabileceğini öne sürmüştür: Duygusal olarak gelişmemiş, zayıf tip ve hırslı, maskülen, saldırgan, baskın tip (aktaran Hammer Burns ve Covington, 2006). Zayıf kadın tipi için annesinden ayrışmakta zorlandığını, öfke ile ilişkili duygularını açık bir şekilde ifade edemediğini, cinsellikten, annelikten, hamilelikten ve doğumdan korktuğunu, bu yüzden de doğurganlığını bastırdığını belirtmiştir. Hırslı kadın tipi için ise hamile kaldığında hayattaki tek kimliğinin "anne" olacağından korktuğunu ve hırslı doğası sebebiyle doğacak çocuğu ile rekabete girebileceği için hamile kalamayabileceğini ileri sürmüştür. Psikojenik infertil erkeklerin ise baskın anne figürlerine sahip olduğunu, oğullarının da anne sevgisinden yoksun kalmamak, ahlaki kurallara uymak ya da ebeveyn olmaya ilişkin karmaşık duygular sebebiyle bu sorunu yaşadıklarını belirtmiştir (Belonoschkin, 1962; Rubenstein, 1951). Genel olarak, infertilite ile ilgili teşhis ve tedavi yöntemlerinin gelişmesi ile birlikte, psikojenik infertilite modelinden vazgeçilmiştir (Denber, 1978; Edelmann ve Connolly, 1986; Walker, 1978).

İnfertilitenin teşhisi ve tedavisi ile ilgili tıbbi açıklamalar yapıldıkça, tanının bireyler üzerindeki psikolojik sonuçları ile ilgili görüşler ortaya atılmıştır. Amerika Birleşik Devletleri'nde 1970'li yıllarda in- fertilite tanısının ve tedavisinin hem bireyi hem de çifti duygusal olarak zorlayıcı olduğunu vurgulayan psikolojik sonuç yaklaşımları ortaya atılmıştır (Stanton ve Dunkel-Schetter, 1991). Bu kapsamda infertilite tedavisi gören çiftlere psikolojik destek vermenin önemi belirtilmiştir. Bu teori gelişim modelleri, evre (stage) modelleri, kriz teorisi ve yas teorileri ile geliştirilmiştir. Bebek sahibi olamamakla, çiftin yetişkinliğin beklentilerinden yakınlık ve üretkenliği tamamlayamadığı, yaşanan krizle çiftin dengeden uzaklaştığ1, rol ve beklenti kaybı olduğu için çiftin yas sürecinin evrelerini yaşadığı belirtilmiştir (Stanton ve Dunkel-Schetter, 1991).

İnfertilite tanısının kişide sebep olduğu psikolojik olumsuzluklar ile ilgili teorilerin ardından, döngüsel psikoloji modeli, psikolojik sonuçlar modeli ve psikososyal bağlam modeli ortaya atılmıştır (van Balen, 2002). Döngüsel psikoloji modeli, kişilerin istedikleri halde çocuk sahibi olamadıklarında, fizyolojik değişiklikler yaşayarak stres seviyelerinin yükseldiğini, böylece infertilite tedavisinin olumsuz etkilendiğini belirtmiştir (Wischmann, 2003). Diğer bir ifadeyle, infertilitenin getirdiği psikolojik stresin, tedavinin biyolojik süreçlerini etkileyebileceği öne sürülmüştür. Psikolojik sonuçlar modeli (Wischmann, Stammer, Gerhard ve Verves, 2002) döngüsel model ile benzer olarak zihin-beden ilişkisini vurgulayarak, psikobiyolojik faktörlerin gebe kalma ve tedaviye etkisine vurgu yapmıştır. Bu iki model ile infertilite tanısının kişilerin psikolojik iyilik halini etkilediği, bu durumun sebep olduğu fizyolojik değişikliklerin ise infertilite tedavisini olumsuz yönde etkilediği görüşü ortaya atılmıştır. Psikososyal bağlam modeli ise infertilitenin sosyal yapıda (evlilik, aile, toplum ve kültür) ve bağlamda (kültür ve din gibi) ne şekilde deneyimlendiğini açıklamıştır (Greil, 1997). İnfertilitenin travmatik bir yaşantı olabileceği, sadece birey bazında ele alınmaması, bireyin, çiftin ve sosyal çevrenin bağlamında ele alınmasının önemli olduğu belirtilmiştir. Böylece infertilite tek bir olay olarak değil, birbirinden bağımsız olaylar zinciri olarak ele alınmıştır. Daha bütüncül bir yaklaşıma sahip olan bu model, bireyin/çiftin infertilite deneyimlerini etkileyen kültürel, dini ve çevresel faktörleri, infertilite tedavisi veren tıbbi servislerin tutumunu, tedavi için yapılan tıbbi turizmi, tedavinin kabul ve reddini belirleyen tüm ilişkileri kapsamıştır. Zihin-beden ilişkisine vurgu yapan ve kültürel bağlamın önemini vurgulayan modellerin yanı sira infertilite, kayıp ve yas çerçevesinde de ele alınmıştır. İnfertiliteye özgü keder ve yas yaklaşımına göre, infertilitenin getirdiği kayıplar, kişinin ya da çiftin sağlığını, yaşam hedeflerini, konumlarını, saygınlıklarını, özgüvenlerini, doğurganlık varsayımlarını, özel hayatlarını, beden üzerindeki kontrollerini, bebeksiz bir hayat olasılıklarını içerebilir (Kuchenhoff, 1999; Lukse ve Vacc, 1999). Ebeveyn olmak ve çocuk sahibi olmak ile 
ilgili arzuların düzeyi arttıkça, kederin seviyesi de artmaktadır. İnfertilite tanı süreci şok, inkar, öfke, suçlama, utanç, suçluluk gibi keder ve yas aşamaları ile benzerlik gösterebilir. Çiftin infertilitenin getirdiği kayıplara ilişkin yas tepkisi farklı olabilir. Ortak kayba ilişkin olarak, kadınlar duygularını ifade ederken, erkekler duygusal olarak uzaklaşmayı tercih edebilirler (Burns ve Covington, 1999). Diğer taraftan, infertiliteye ilişkin kayıpların kabul edilmemesi ve ele alınmaması, çiftin uzun dönemde infertilite ile baş etme becerilerini, aile kurma ve tedavi seçeneklerini değerlendirmelerini olumsuz yönde etkileyebilir.

Bireysel kimlik teorileri bakış açısına göre ise infertilite yaşantısının kabullenilmesi, infertilitenin getirdiği narsisistik yaralarla baş etmek için gereklidir. Bu yaklaşıma göre, infertilite kişinin benliğini, eksiklik, umutsuzluk ve utanç gibi duygular yaratarak değiştirebilmektedir (Leon, 1990). Kadınlar kişisel ve sosyal rolleri/beklentileri yerine getiremedikleri için yetersiz ve eksik hissedebilir, erkekler ise aşağılık duygusu, mahcubiyet ve kızgınlık yaşayabilirler. Süreci farklı şekillerde deneyimleseler de değişken bir benlik değerine sahip olurlar. Bu bağlamda, kişilerin infertilite tanısını bireysel kimlikleriyle, benlik kavramları ve tanımlarıyla bütünleştirmeleri beklenmektedir (Olshansky, 1987).

Psikoloji tarihi penceresinden bakıldığında, 1990'larda stresin psikolojik sağllğa etkisi ile ilgili çalışmalar ivme kazanmıştır. Bu gelişmelerle uyumlu olarak, Stanton ve Dunkel-Schetter'e (1991) göre stres ve baş etme yaklaşımlarını infertilite tedavisinde kullanmak mümkündür, çünkü infertilite öngörülemezliği, olumsuz olma durumu, kontrol edilemezliği ve belirsizliği ile bireylere stres yaşatır. Kişi kanser, genetik bir rahatsızlık ya da farklı tıbbi sebeplerle gelişen infertilite nedeniyle öncelikle akut bir stres yaşayabilir ve belirli baş etme becerileri ile bu sürece uyum sağlayabilir. Ancak birçok çift, infertiliteyi duygusal zorluklar, zorlayıcı tıbbi müdahaleler içeren, duygusal yaşantılara ve evliliğe ilişkin dengeyi oluşturabilmek için tedavi süreci boyunca farklı baş etme becerileri gerektiren, uzun dönemli bir stres unsuru olarak deneyimlemektedir. İster akut ister kronik bir stres unsuru olsun, infertilite yaşam hedeflerine, kişisel kaynaklara, geçmişten getirilen çözülememiş problemlere ilişkin çözümsüz bir problem olarak algılanan yaşamsal bir kriz olarak görülebilmektedir (Stanton ve Dunkel-Schetter, 1991).

Benzer yıllarda aile sistemleri yaklaşımı da infertilite tanısını kendi perspektifinden ele almıştır. Aile sistemleri yaklaşımına göre, infertilite sadece çiftin değil kuşaklararası ailelerin gelişimsel bir problemidir (Daly, 1991). Çifti ebeveyn olmaktan, çiftin anne babasını büyükbaba, büyükanne olmaktan, çiftin kardeşlerini yeğenleri olmasından uzak tutar. Özlenen bebeğin çift tarafından arzu edildiği sürece psikolojik olarak var olması; ancak fiziksel olarak yoklu- ğu, çiftin belirsiz sınırlar yaratmalarına sebep olabilir. İstenen çocuğa kavuşamamak, çiftin kendilerine ya da birbirlerine olumsuz etiketler yüklemelerine, özel hayatlarının ihlal edilmesinden korunmak için ise aile ve arkadaşlarına katı sınırlar çizmelerine yol açabilir (Daly, 1991). Bazı çiftler de çok geçirgen sınırlara sahip olup, eşiyle olan özel hayatlarına ilişkin birçok konuyu başkaları ile paylaşabilir.

Evre yaklaşımlarına göre (Read, 1995) ise infertilitenin getirdiği yas süreci Kübler-Ross'un (1973) (inkar, öfke, pazarlık, depresyon ve kabul evreleri), Worden'ın (1991) (kaybın gerçekliğini kabul etme, yasın acısını yaşama, olası sevilen kişinin kaybının kabul edildiği çevreye uyum sağlama, duygusal yer değiştirme ile hayata devam etme evreleri) ve Egan'ın (2013) (keşfetme, yeniden anlamlandırma ve harekete geçme evreleri) modelleri ile benzerlik taşımaktadır. Read'in (1995) infertilite danışmanlık modeli ise tanı koyma, duyguları yönetme, hareket planlama, tıbbi tedaviyi anlama ve tedavinin sonuçlarını bekleme aşamalarını içerir. Diamond, Kezur, Meyers, Scharf ve Weinshel, (1999) infertilitenin beş aşamasını (şafak, harekete geçme, tutulma, çözülme, miras) tanımlamışlardır. Şafak aşamasında, çiftler bir problemleri olabileceğinin zamanla farkına varıp tıbbi yardım aramaya başlarlar. Harekete geçme aşaması tanı testlerinin yapıldığı ve sonuçlar istendiği gibi çıkmadığında şok ve inkar tepkilerinin verildiği süreçtir. Tutulma aşamasında çift test ve tedaviye devam etmektedir, ancak beklenen süreç yani çocuk sahibi olma ve anne/baba olma gerçekleşmemiştir. Tedavi istenildiği gibi gitmediğinde çift farklı seçenekleri gözden geçirmeye başlar. Çözülme aşaması tedaviyi sonlandırma, genetik olarak çiftin ortak bir çocuğu olamayacağının kabulü, yasın ardından da evlat edinme ya da çocuksuz bir hayata yeniden odaklanma gelir. Miras aşaması ise infertilitenin miras olarak bıraktığı cinsellik, evlilik ve ebeveynlik ile ilgili olumlu/olumsuz deneyimleri, psikolojik travma ya da büyümeyi kapsamaktadır.

İnfertiliteye özgü geliștirilen veya uyarlanan modeller bağlamında infertiliteye psikolojik müdahale bağlamında kullanılan teknikler, amaç, hedef ve kapsamın neler olduğunun irdelenmesinin önemli olduğu düşünülmektedir.

\section{İnfertiliteye psikolojik müdahale}

İlgili alanyazında, infertilite tanısı almış bireylere yaşadıkları durum ile daha iyi başa çıkabilmeleri için infertilite danışmanlığı veya psikoterapi almaları önerilmektedir (Domar ve ark., 2000; Hämmerli, Znoj ve Barth, 2009; Noorbala ve ark., 2008; Peterson ve ark., 2012). Benzer şekilde infertilite tanısının ortaya çıkardığı olumsuz psikolojik sonuçlar nedeniyle çiftlerin 1/5'inin psikolojik destek aradıkları ifade edilmiştir (Boivin ve Kentenich, 2002). Çiftlerdeki 
psikolojik destek arayıșına rağmen, infertilite kliniklerinde tedavi sürecini yürüten doktorların, hastaları psikolojik destek almaya daha az oranda yönlendirdikleri de bulunmuştur (Pasch ve ark., 2016). İnfertilite sürecindeki psikososyal müdahalelerin olumsuz duyguları azalttığı (Wisman ve Goldenberg, 2005), psikolojik iyilik halini ve evlilik doyumunu artırdığ 1 , hamilelik oranlarını da olumlu yönde etkilediği belirtildiği (Ying, Wu ve Loke, 2015) için infertiliteye psikolojik müdahale konusunda çiftlerin, doktorların ve alanda çalışan psikologların farkındalık kazanmalarının son derece önemli olduğu düşünülmektedir.

İnfertiliteye psikolojik müdahalelerin temel amac1, (a) tedavi süresince ve sonrasında çiftin yaşam kalitesini artırmak, (b) infertilitenin olumsuz etkisini azaltmak, (c) uzun dönemde vereceği zararı ve stresi önlemek için infertilite deneyimini psikolojik büyüme ile aşmayı sağlamak, (d) çocuk sahibi olmaktan vazgeçme, evlat edinme ya da koruyucu ailelik ile ailesini şekillendirmiş çiftin sürece uyumunu sağlamaktır (Hammer Burns ve Covington, 2006).

Psikososyal değerlendirme; bireyin ve çiftin yaşam öyküleri ve psikiyatri geçmişleri ile ilgili bilgi almayı; infertilitenin evlilikleri, psikolojik sağlıkları, günlük hayattaki farklı bireylerle olan ilişkileri, cinsel yaşamları üzerine etkisi ile ilgili görüşme yapıp veri toplamayı içerir. Psikolojik testlerle desteklendiğinde tedavi planı netleşir. Diğer psikolojik tedavi yöntemlerinde olduğu gibi, tedavi planı hasta ya da çiftle yapılan dikkatli değerlendirmeler sonrasında, psikoterapi ve/ya psikiyatrik ilaç yönlendirmeleri ile ilgili müdahaleleri kapsar. Bu noktada psikolojik destek veren uzmanın, infertilite tedavisi sürecinden geçen bireyin ve çiftin bu duruma özgü zorluk ve meydan okumaları hakkında bilgi sahibi olması gerekir (Şensözen, 2010).

İnfertilite tedavisinde psikoterapist uygun bulduğu kuramsal ve terapötik yaklaşımlara göre psikodinamik terapi, bilişsel davranışçı terapi, çözüm odaklı kısa süreli terapi, cinsel terapi, krize müdahale, yas danışmanlığ gibi çeşitli psikoterapi yöntemleri (bireysel, çift/aile, destek grupları ve terapi grupları olarak) uygulayabilir. İnfertilite kaynaklı olsun veya olmasın kişisel stresin ve günlük hayatta işlev bozukluğunun olduğu durumlarda bireysel psikoterapi önerilebilir (Hammer Burns ve Covington, 2006).

İlişkide ya da evlilikte iletişim sorunları, karar verme kaygısı ya da çatışma çözme problemi olan durumlarda çift terapisi gerekebilir. İnfertilite, kişisel bir problem olarak algılanmak yerine çiftin problemi olarak algılandığında psikolojik iyilik hali açısından yol alınacağı bilinmektedir. Örneğin, çiftin beraberce yaşadıkları kayıp ile ilgili yas tutmak, cinselliklerinin kısıtlanması ve tedavinin getirdiği finansal yükümlülükler, infertilite problemi olan bireyin değil, çiftin problemi olarak görülüp, birlikte aşılması önerilmektedir (Hammer Burns ve Covington, 2006).
Psikolojik büyüme gerektiren, kendisinin başka bakış açılardan nasıl göründüğünü sorgulamak ve araştırmak isteyen kişilere grup terapisi önerilmektedir. Grup üyeleri ile yapılan paylaşımlar sayesinde infertilite deneyiminin getirdikleri konusunda yalnız olunmadığı, etiketlenme ve uzaklaşma ile ilgili kayg1ların ortak paylaşımlar olduğu anlaşılabilir (Yalom, 2012). Grup terapilerinin bazılarının tıbbi tedavi sonuçlarına iyi yönde katkılar sağladığı da bulunmuştur (Boivin, 2003). Törenli-Kaya'nın (2018) güncel araştırmasında da kadınların infertilite tedavisi sırasında destek grubu çalışmalarına katıldıklarında, benzer deneyimi yaşayan diğer kadınlarla paylaşımları sayesinde çocuk sahibi olmaya ilişkin streslerinin ve süreçle ilgili gerçekçi olmayan beklentilerinin azaldığı belirtilmiştir. İnfertilite tedavisi gören kişilerin sosyal destek almaları önerilmesine rağmen, tanılarının sonucunda hissettikleri etiketlenme korkusu nedeniyle kendilerini sosyal ortamlardan uzaklaştırdıkları (Mindes, Ingram, Kliewer ve James, 2003) ve grup terapisine devam etmede problemler yaşayabildikleri belirtilmiştir. İnfertilite ile ilgili bir bilgi edinme kaynağı olan internetin, grup paylaşımları için de kullanılabileceği, böylece kişilerin etiketlenme korkusu olmadan, gerekirse gerçek kimliklerini de gizleyerek yarar sağlayabilecekleri ifade edilmiştir (Greil, Slauson-Blevins ve McQuillan, 2010). Türkiye'de bir klinik psikoloğun internet üzerinden infertilite tedavisi alan bireylerle yürüttüğü grup terapisi çalışmasında, deney grubunun kontrol grubuna göre yaşadığı deneyime daha fazla anlam bulabildiği, infertilite deneyimini daha kontrol edilebilir bulduğu ve özyeterlilik puanlarının daha yükssek olduğu görülmüştür (Şimşek-Alphan, 2018).

İnfertil çiftlerden bazılarında tıbbi tedavi süreçleri defalarca denendiği halde gebelik ile sonuçlanmaz ve çift ebeveyn olmak ile ilgili düşüncelerini gözden geçirmek zorunda kalır. Bu süreçte, aile kavramının yeniden tanımlanıp ele alınması, hamilelik/doğum süreçlerini deneyimlememenin ve biyolojik olarak ortak bir çocuğa sahip olamamanın yasının tutulması gerekebilir. Bazı çiftler bu süreçleri deneyimledikten sonra, çocuksuz bir yaşantıyı tercih edip, tıbbi tedaviyi bırakabilir, sadece çift olmanın getirdiği özgürlügü deneyimleyebilir, hayatlarına yeni hedefler ve üretkenlik yolları katabilirler. Gelișim aşamalarına göre üretken olmanın sadece çocuk sahibi olmakla kazanılmayacağı, farklı yollarla bu aşamayı kaydetmenin mümkün olduğu anlaşılabilir. Bazı çiftler ise infertiliteyi sosyal olarak izole edilme ve etiketlenme olarak algılayıp, boşanabilir, terk edebilir ya da edilebilirler. Diğgerleri ise evlat edinme ve koruyucu aile olma kararlarını gündeme alabilirler (Hammer Burns ve Covington, 2006). 


\section{Sonuç}

İnfertilite tanısı oldukça uzun bir tarihsel sürece sahip olsa da ele alındığı psikolojik çerçeve, tıbbi yenilikler ve farklı psikoloji yaklaşımlarının ortaya çıkması ile farklılaşmıştır.

İnfertilite tedavisinde psikolojik destek sağlamak, nispeten yeni gelişen, gün geçtikçe yeni çalışmalarla büyüyen, birçok disiplinden uzmanların tedavide yer aldığ 1 bir süreçtir. Bu çalışmanın amacı tarihsel bakış açısından yararlanarak, infertilite tedavisi alan kişiler ya da çiftlerle çalışan psikoterapistlere tedaviyi ele alabilecekleri çerçeveyi sunmak ve farklı psikolojik müdahaleleri belirtmektir. Bu derleme çalışmasında infertilitenin psikolojik etkileri Freudyen psikanalitik bakış açıları, psikolojik sonuç yaklaşımları, döngüsel psikoloji modeli, psikolojik sonuçlar modeli, psikososyal bağlam modeli, kayıp ve yas bakış açısı, bireysel kimlik kuramları, stres ve baş etme yaklaşımları, aile sistemleri yaklaşımları ve evre yaklașımları açısından ele alınmıştır. İnfertilite tanısının psikolojik etkileri ile ilgili kuramsal ve uygulama bilgi birikimi olan bir klinik psikoloğun tedavi sürecini takip eden ekibe dahil olması ile birlikte, çiftin psikiyatrik öyküsü alınabilir, tedavi sürecinin getirdiği duygu, düşünce ve davranışlar ele alınabilir, gerektiği durumlarda psikolojik testlerle de desteklenerek tedavi planı oluşturulabilir. Tedavi bireysel psikoterapi, çift ya da aile terapisi, benzer deneyimi yaşayan kişilerle destek/paylaşım grupları ya da grup psikoterapisi olarak uygulanabilir. Yapılacak ileri araştırmalar ile bu alanda çalışan uzmanlara etkin tedavi yöntemlerinin ve bu yöntemleri uygulamada gerekli olan niteliklerin neler olduğu konusunda yeni ufuklar açılacağı düşünülmektedir.

\section{KAYNAKLAR}

Altıntop, İ. ve Kesgin, B. (2018). İnfertilite tedavisi gören çiftlerin kaygı, psikolojik dayanıklılık düzeyleri ile başa çıkma stratejileri. Uluslararası Sosyal Araştırmalar Dergisi, 11(55), 1-14.

Belonoschkin, B. (1962). Psychosomatic factors and matrimonial infertility. International Journal of Fertility, 7, 29-36.

Benedek, T. (1952). Infertility as a psychosomatic defense. Fertility and Sterility, 3, 527-41.

Boivin, J. ve Kentenich, H. (2002). Guidelines for counseling in infertility. ESHREMonographs: Oxford University Press.

Boivin, J. (2003). A review of psychosocial interventions in infertility. Social Science Medicine, 57, 2325-41.

Burns, L. H. ve Covington, S. N. (1999). Infertility counseling: A comprehensive handbook for clinicians. New York: Parthenon.

Coleman, R., Morison, L., Paine, K., Powell, R. A. ve Walraven, G. (2006). Women's reproductive health and depression. Social Psychiatry \& Psychiatric Epidemiology, 41, 720-727.
Cooper-Hilbert, B. (1998). Infertility and involuntary childlessness. New York: W. W. Norton \& Company.

Daly, K. J. (1991). Crisis in genealogy: Facing the challenges of infertility. H. I. McCubbin ve E. A. Thompson (Ed), Resilience in Families içinde (ss. 1-39). Sage Publications.

Daniluk, J. ve Tench, E. (2007). Long term adjustment of infertile couples following unsuccessful medical intervention. Journal of Counseling \& Development, 85, 89-100.

Denber, H. C. B. (1978). Psychiatric aspects of infertility. Journal of Reproductive Medicine, 20, 23-29.

Deyhoul, N., Mohamaddoost, T., Hosseini, M. ve Dezelic, M. (2017). Meaning constructs and meaning-oriented techniques: Clinical applications of meaning and existential exploration. Journal of Constructivist Psychology, 30(1), 32-41.

Diamond, R., Kezur, D., Meyers, M., Scharf, C. N. ve Weinshel, M. (1999). Couple therapy for infertility. New York: The Guilford Press.

Domar, A. D., Clapp, D., Slawsby, E., Kessel, B., Orav, J. ve Freizinger, M. (2000). The impact of group psychological interventions on distress in infertile women. Health Psychology, 19(6), 568.

Drosdzol, A. ve Skrzypulec, V. (2009). Depression and anxiety among Polish infertile couples- an evaluative prevalence study. Journal of Psychosomatic Obstetrics \& Gynecology, 30(1), 11-20.

Edelmann, R. J. ve Connolly, K. J. (1986). Psychological aspects of infertility. British Journal of Medical Psychology, 59, 209-219.

Egan, G. (2013). The skilled helper: A problem management and opportunity-development approach to helping. Cengage Learning.

Fisher, J. R., Hammarberg, K. ve Baker, G. H. (2008). Antenatal mood and fetal attachment after assisted conception. Fertility and Sterility, 89(5), 1103-1112.

Greil, A. (1997). Infertility and psychological distress: A critical review of the literature. Social Science Medicine, 45, 1679-1784.

Greil, A. L., Slauson-Blevins, K. ve McQuillan, J. (2010). The experience of infertility: A review of recent literature. Sociology of Health \& Illness, 32(1),140-162.

Hammer Burns, L. ve Covington, S. N. (2006). Psychology of infertility. S. N. Covington ve L. Hammer Burns (Ed). Infertility Counseling: A Comprehensive Handbook for Clinicians içinde (ss. 1-19). New York: Cambridge University Press.

Hämmerli, K., Znoj, H. ve Barth, J. (2009). The efficacy of psychological interventions for infertile patients: A meta-analysis examining mental health and pregnancy rate. Human Reproduction Update, 15(3), 279-295.

Karjane, N. W., Stovall, D. W., Berger, N. G. ve Svikis, D. S. (2008). Alcohol abuse risk factors and psychiatric disorders in pregnant women with a history of infertility. Journal of Women's Health, 17(10), 1623-1627.

Kübler-Ross, E. (1973). On death and dying. Routledge.

Kuchenhoff, J. (1999). Unfulfilled desire for children-what is the grief for men? Therapeutische Umschau, 56, 260-264.

Lamas, C., Chambry, J., Nicolas, I., Frydman, R., Jeammet, P. ve Corcos, M. (2006). Alexityhmia in infertile 
women. Journal of Psychosomatic Obstetrics \& Gynecology, 27(1), 23-30.

Leon, I. (1990). When a Baby Dies: Psychotherapy for Pregnancy and Newborn Loss. New Haven: Yale Press.

Lukse, M. P. ve Vacc N.A. (1999). Grief, depression, and coping in women undergoing infertility treatment. $\mathrm{Ob}$ stetrics and Gynecology, 93, 245-251.

Lykeridou, K., Gourounti, K., Deltsidou, A., Loutradis, D. ve Vaslamatzis, G. (2009). The impact of infertility diagnosis on psychological status of women undergoing fertility treatment. Journal of Reproductive and Infant Psychology, 27(3), 223-237.

Mayo Clinic (2011). Infertility, causes. 12 Haziran 2018, http://www.mayoclinic.com/health/infertility/DS0310/ DSECTION=causes

Mindes, E. J., Ingram, K. M., Kliewer, W. ve James, C. A. (2003). Longitudinal analyses of the relationship between unsupportive social interactions and psychological adjustment among women with fertility problems. Social Science Medicine, 56(10), 2165-2180.

Noorbala, A. A., Ramazanzadeh, F., Malekafzali, H., Abedinia, N., Forooshani, A. R., Shariat, M. ve Jafarabadi, M. (2008). Effects of a psychological intervention on depression in infertile couples. International Journal of Gynecology \& Obstetrics, 101(3), 248-252.

Noorbala, A. A., Ramezanzadeh, F., Abedinia, N. ve Naghizadeh, M. M. (2009). Psychiatric disorders among infertile and fertile women. Social Psychiatry \& Psychiatric Epidemiology, 44, 587-591.

Olshansky, E. F. (1987). Identity of self as infertile: An example of theory-generating research. Advances in Nursing Science, 9, 54-63.

Pasch, L. A., Holley, S. R., Bleil, M. E., Shehab, D., Katz, P. P. ve Adler, N. E. (2016). Addressing the needs of fertility treatment patients and their partners: Are they informed of and do they receive mental health services? Fertility and Sterility, 106(1), 209-215.

Peterson, B., Boivin, J., Norré, J., Smith, C., Thorn, P. ve Wischmann, T. (2012). An introduction to infertility counseling: A guide for mental health and medical professionals. The Journal of Assisted Reproduction and Genetics, 29(3), 243-248.

Population Council. (2004). Infertility: Looking back. New Delhi: Population Council (Ed), Looking Forward: A Profile of Sexual and Reproductive Health in India içinde (ss. 67-72).

Read, J. (1995). Counselling for Fertility Problems. Londra: Sage Publications Ltd.

Rubenstein, B. B. (1951). An emotional factor in infertility: A psychosomatic approach. Obstetrical \& Gynecological Survey, 6(5), 756.

Speroff, L., Glass, R. H. ve Kase, N. G. (1994). Clinical gynecologic endocrinology and infertility ( $5^{\text {th }}$ Ed.). Baltimore: Williams \& Wilkins.

Schwerdtfeger, K. L. (2009). Trauma of pregnancy loss and infertility among mothers and involuntarily childless women in the United States. Journal of Loss and Trauma, 14, 211-227.

Stanton, A. L. ve Dunkel-Schetter, C. (1991). Psychological adjustment to infertility. A. L. Stanton ve C. Dunkel-Schetter (Ed), Infertility: Perspectives from Stress and Coping içinde (ss. 3-16). New York: Plenum Press.
Şensözen, G. (2010). Tüp Bebeği Beklerken. İstanbul: İş Bankası Kültür Yayınları.

Şimşek-Alphan, Y. (2018). An interpretative phenomenological analysis of meaning-making of infertility among infertile Turkish women: Developing and testing the effectiveness of an online intervention program in meaning making (Yayımlanmamış doktora tezi), Orta Doğu Teknik Üniversitesi: Ankara.

Törenli-Kaya, Z. (2018). Predictors of maternal prenatal attachment and pregnancy adaptation in women conceived via assisted reproductive techniques: A mixed method study (Yayımlanmamış doktora tezi), Orta Doğu Teknik Üniversitesi: Ankara.

Turkish Medical Association. (2006). Turkish Health Sta$\begin{array}{llll}\text { tistics } & 2006 . & 12 & \text { Haziran }\end{array}$ http://www.ttb.org.tr/kutuphane/istatistik2006.pdf

van Balen, F. ve Bos, H. M. W. (2004). Infertility, culture and psychology in worldwide perspective, Journal of Reproductive and Infant Psychology, 22(4), 245-247. van Balen F. (2002). The psychologization of infertility. M.C. Inhorn ve F. Van Balen (Ed), Infertility Around the Globe: New Thinking on Childlessness, Gender, and Reproductive Technologies içinde (ss. 7998). Los Angeles, CA: University of California Press.

Walker, H. E. (1978). Psychiatric aspects of infertility. Urologic Clinics of North America, 5, 481-488.

Watkins, K. J. ve Baldo, T. D. (2004). The infertility experience: biopsychosocial effects and suggestions for counselors. Journal of Counseling and Development, 82, 394-402.

Wischmann, T. Stammer, H., Gerhard, I ve Verves, R. (2002). Couple counseling and therapy for the unfulfilled desire for a child: The two-step approach of the 'Heidelberg infertility consultation. B. Strauss (Ed), Involuntary Childlessness: Psychological Assessment, Counseling, and Psychotherapy içinde (ss. 127-150). Seattle: Hogrefe \& Huber Publishers.

Wischmann, T.H. (2003). Psychogenic infertility: Myths and facts. Journal of Assisted Reproductive Genetics, 20, 485-494.

Wisman, A. ve Goldenberg, J. L. (2005). From the grave to the cradle: Evidence that mortality salience engenders a desire for offspring. Journal of Personality and Social Psychology, 89(1), 46-61.

Worden, J. W. (1991). Grief counselling and grief therapy: A handbook for the mental health professional. London: Routledge.

Yalom, I. (2012). Grup Psikoterapisinin Teori ve Pratiği. İstanbul: Kabalcı Yayınları.

Yeşiltepe Oskay, U., Kızılkaya Beji, N. ve Serdaroğlu, H. (2010). The issue of infertility and sexual function in Turkish women. Sexuality \& Disability, 28, 71-79.

Ying, L. Y., Wu, L.H. ve Loke, A. Y. (2015). Gender differences in experiences with and adjustments to infertility: A literature review. International Journal of Nursing Studies, 52(10), 1640-1652. 